\title{
Best practices for avoiding dominant experimental bias in analysis of multielectrode array signals
}

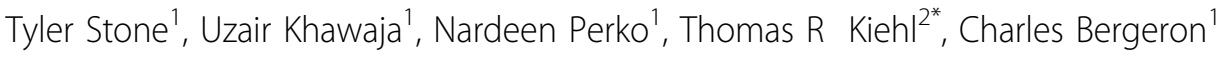 \\ From The Twenty Third Annual Computational Neuroscience Meeting: CNS*2014 \\ Québec City, Canada. 26-31 July 2014
}

Multielectrode arrays (MEA) are broadly used for in vitro cell culture observation. Complete realization of this platform's potential to the study of disease and development depends on the capability to make 1) reliable and repeatable observations, 2) neuronal network behavior characterizations, and 3) meaningful comparisons between cultures. Using an extensive, previously published, set of recordings [3] we demonstrate that naïve processing of this data leaves us vulnerable to bias from measurement error.

We utilize 878 recordings from embryonic rat cortex cell cultures collected from 60-electrode, grid-type (200 $\mu \mathrm{m})$ MEA's. We modeled each recording as a 60-node directed weighted graph with weights describing electrode connectivity and nodal clustering coefficients [1] as features. Principal components analysis (PCA) reduced the dimensionality of this feature space [2]. We observe a dense core of recordings showing weak spike activity, and 3 classes defined by batch (labeled in Figure 1A). Surprised at this structure, we sought a non-biological explanation. We identified 13 defective or biased electrodes as sources of systematic measurement error. Removing the affected electrodes produced a more complex interplay of interand intra-batch variability (Figure 1B).

Bias from defective electrodes can be avoided wholly by proper documentation of experimental conditions. This
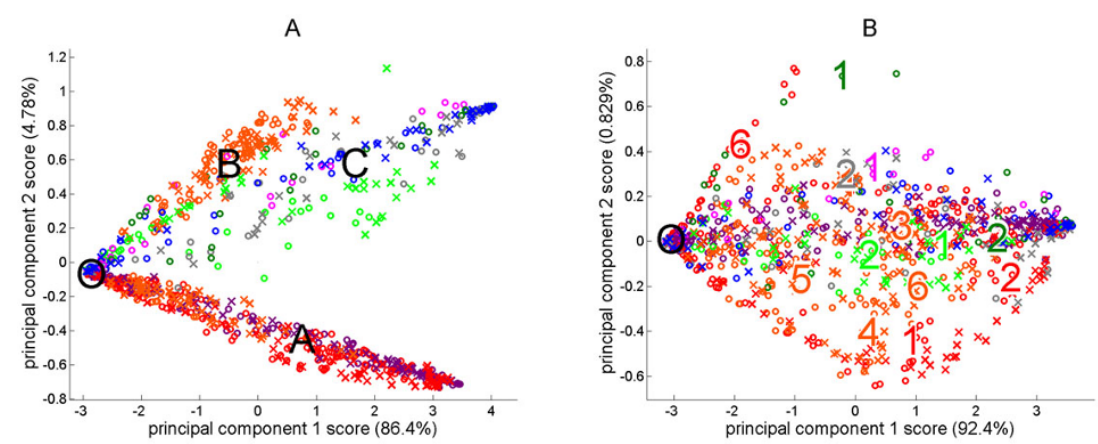

Figure 1 (A) Principal components analysis biplots using all 60 electrodes. Each marker is a recording. Colors indicate batches: Batch 1 (purple) Batch 2 (red), Batch 3(orange), Batch 4 (light green), Batch 5 (grey), Batch 6 (blue), Batch 7 (pink), and Batch 8 (dark green). The large black circle is the dense core of recordings showing weak spike activity. Classes A, B and C are also labeled. (B) PCA biplots using the 47 electrodes following deletion of biased ones. Some regions are associated with specific cultures identified by culture numbers and batch colors.

\footnotetext{
* Correspondence: tomkiehl@neuralsci.org

${ }^{2}$ Neural Stem Cell Institute, Rensselaer, NY, 12144, USA

Full list of author information is available at the end of the article
} 
highlights the need for best practices when recording MEA signals. Our analysis highlights possibilities for postexperimental review to identify unknown issues and retroactively handle them. Thereupon, we make a case for transparency in data reporting and propose best practices for experimental and analysis phases.

\section{Authors' details}

${ }^{1}$ Analytics Lab, Albany College of Pharmacy and Health Sciences, Albany, NY, 12208, USA. ${ }^{2}$ Neural Stem Cell Institute, Rensselaer, NY, 12144, USA.

Published: 21 July 2014

\section{References}

1. Bullmore E, Sporns O: Complex brain networks: graph theoretical analysis of structural and functional systems. Nat Rev Neurosci 2009, 10:186-198.

2. Jolliffe IT: Principal Component Analysis,. New York: Springer; Second 2002.

3. Wagenaar DA, Pine J, Potter SM: An extremely rich repertoire of bursting patterns during the development of cortical cultures. BMC Neurosci 2006, $7(11)$.

doi:10.1186/1471-2202-15-S1-P208

Cite this article as: Stone et al.: Best practices for avoiding dominant experimental bias in analysis of multielectrode array signals. BMC Neuroscience 2014 15(Suppl 1):P208.

\section{Submit your next manuscript to BioMed Central} and take full advantage of:

- Convenient online submission

- Thorough peer review

- No space constraints or color figure charges

- Immediate publication on acceptance

- Inclusion in PubMed, CAS, Scopus and Google Scholar

- Research which is freely available for redistribution

Submit your manuscript at www.biomedcentral.com/submit 